\title{
Transport Processes in Porous Media by Self-Potential Method
}

\author{
Valeria Giampaolo, Daniela Calabrese, and Enzo Rizzo \\ Consiglio Nazionale delle Ricerche, Istituto di Metodologie per l’Analisi Ambientale, Laboratorio Hydrogeosite, \\ Contrada Santa Loja, 85050 Tito, Italy \\ Correspondence should be addressed to Enzo Rizzo; enzo.rizzo@imaa.cnr.it
}

Received 1 October 2015; Accepted 20 December 2015

Academic Editor: Pantelis Soupios

Copyright (C) 2016 Valeria Giampaolo et al. This is an open access article distributed under the Creative Commons Attribution License, which permits unrestricted use, distribution, and reproduction in any medium, provided the original work is properly cited.

\begin{abstract}
A controlled diffusion/infiltration column experimental activity was carried out with the aim of monitoring the leakage of a salty water plume by time-lapse self-potential (SP) measurements. In particular, three tracer tests with different $\mathrm{NaCl}$ concentrations $\left(6.00,1.00\right.$, and $\left.0.25 \mathrm{~g} \mathrm{~L}^{-1}\right)$ were performed and all the measured SP signals showed a sharp reduction corresponding to the arrival of saline front with negative electrical potential values $(-78.99 \pm 3.24 \mathrm{mV},-54.52 \pm 2.28 \mathrm{mV}$, and $-24.12 \pm 1.21 \mathrm{mV})$ which decrease with increasing volume of tracer introduced into the column. Then, measured self-potential values were converted into salt concentration ones by the Planck-Henderson equation and sand diffusion $(D)$ and longitudinal dispersivity $\left(\alpha_{L}\right)$ values were estimated by modelling the transport equations in the COMSOL Multiphysics environment. Finally, the results show that measured and estimated $\mathrm{NaCl}$ concentrations are well correlated.
\end{abstract}

\section{Introduction}

One of the most difficult tasks for the hydrogeologist is to characterize solute transport mechanism in heterogeneous aquifers; in fact, flow pathways and velocity and the medium permeability are necessary information to evaluate the possible contamination effect and to design and optimize remediation strategies. Usually, subsoil heterogeneities, linked to rock texture, pore-space geometry, and mineralogy, affect solute transport processes that could display a heterogeneous behaviour and significant spatial-temporal changes of solute concentrations.

As a result of this high variability degree of the involved phenomena, typical measurements, for example, invasive soil and water sampling, are mostly unable to adequately characterize transport properties and processes.

Therefore, in the last year, environmental geophysicists have concentrated their research activity on the development of high resolution geophysical techniques for the study of flow and transport processes. In particular, several works have shown the efficacy of coupling geophysical prospecting and tracer test as a useful device to reconstruct solute transport phenomena in the subsoil [1-4]. In fact, the use of a noninvasive and indirect methodology with a high sampling density, the possibility to acquire data in an automated time-lapse manner, and the ability to modulate the measurement scale by suitable survey strategy make the geophysical methods an important tool for subsurface transport characterization. However, in order to improve the reconstruction of solute transport phenomena in heterogeneous subsoil starting from geophysical imaging techniques, it is necessary to use petrophysical relationships that link geophysical parameters to transport related ones.

The most suited geophysical methods for the transport processes monitoring are techniques sensitive to variations in the subsoil electrical properties. Traditionally, the monitoring of salt plume by geophysical techniques is performed by electrical resistivity tomography (ERT) or ground penetrating radar (GPR) [1-3]; however, also the self-potential (SP) method has been shown to be a suitable tool for monitoring solute transport processes because it is sensitive both to groundwater flow (electrokinetic potential) [5-9] and to electrochemical processes (electrochemical potential) related to gradients of the ionic species chemical potential and redox potential (Eh) in the pore water [10-23]. The most recent efforts have been those to estimate hydrological properties, starting from electrical potential values measured, using coupling equations linked by coupling coefficients 
that describe the groundwater flow and the self-potential phenomena $[3,13,14,24-30]$. One of the approaches consists in converting the measured electrical potential into solute concentration using hydrogeophysical relations [31], and then the estimated solute concentrations, combined with direct hydrologic observations, are used to condition an inversion procedure for calculating medium parameters such as hydraulic conductivity and longitudinal dispersivity. In particular, Maineult et al. $[13,14,29]$ estimated $\mathrm{NaCl}$ plume concentration in sandbox-controlled experiments from SP measurement, while Revil and Jardani [30] assessed, using a stochastic approach, the hydraulic conductivity and dispersivity values of a fine sand using time-lapse self-potential measurements. Moreover, Ikard et al. [32] localized preferential fluid flow pathways in a porous medium by measuring time-lapse electrical potential values during a salt tracer injection in a sandbox experiment. In order to replicate the time-lapse self-potential distribution measured, they performed a synthetic case study and, with a finite element model by COMSOL Multiphysics, they determined the porosity and hydraulic conductivity of the medium.

In this work, the self-potential method was applied to trace in real time the front of a leaking salt plume during three pulse input tracer tests at different salt concentration and estimated the diffusion and the dispersivity parameters of the porous material applying a hydrogeophysical inversion approach. A laboratory experiment was performed at the Hydrogeosite Laboratory of IMAA-CNR of Marsico Nuovo (Italy). The main objective of this study was to analyse in time-lapse the contamination phenomenon by self-potential measurements in the presence of simulated constant water flow and evaluate the transport processes occurring in a homogeneous porous medium in saturated conditions. In detail, a sand column was set up performing a controlled diffusion/infiltration experiment in order to monitor the leakage of a salty water plume by time-lapse self-potential measurements. Finally, a finite element inversion model was implemented with COMSOL Multiphysics software, in order to build a numerical model and to have a comparison between experimental measurements and the modelled one. Moreover, inversion approach refines and improves the interpretation of experimental studies by providing system transport parameters assessment.

\section{Theoretical Background}

The self-potential (SP) method is a passive geoelectrical technique consisting in measuring the electrical potential differences $(V)$ long profiles and/or maps, between two nonpolarisable electrodes driven into the ground, at the surface of the earth, or in boreholes. These voltage differences are linked to electric fields generated by natural sources distributed in the subsoil, produced by various phenomena (hydraulic, chemical, and thermal).

The instrumentation typically used in SP measurement surveys consists of a multimeter, two nonpolarisable electrodes, and electric cables (Figure 1). Currently, there are multichannel systems for SP measurement not only for a

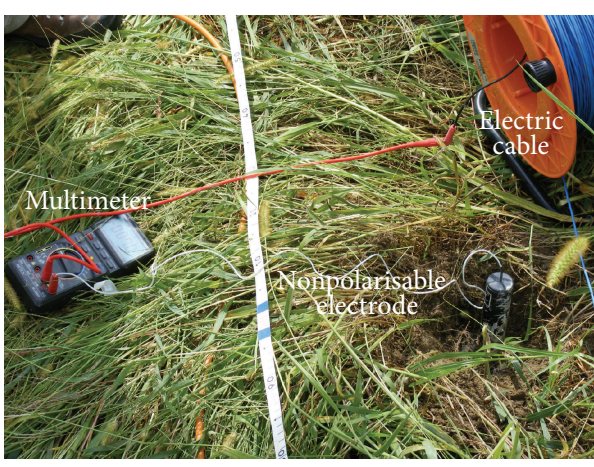

FIGURE 1: Instrumentation for SP measurement [33].

better spatial coverage along profiles or maps, but also for a continuous observation during time of the evolution of the related phenomena [34].

In the last years, the objective of SP interpretation became to solve coupled problems characterized by a system of linear equations, in order to obtain information about where and how the natural electrical current sources generate SP signal measured at surface and how big these sources are.

From Poisson's continuity equation, the general equation for SP signals can be written as follows:

$$
\nabla \cdot(\sigma \nabla \varphi)=\nabla \cdot J_{s}
$$

where $\sigma$ is the bulk electrical conductivity, $\varphi$ is the selfpotential, $J_{s}$ is the external current density (electrical current source), and the total electric current density is divergencefree [17]. The self-potential source mechanisms were firstly theorized in the framework of Onsager's equations for coupled flows $[5,35,36]$ :

$$
\begin{aligned}
& J_{s}=\sum_{i} j_{i}, \\
& J_{i}=-\sum_{k} L_{i k} \nabla x_{k},
\end{aligned}
$$

where $\nabla x_{k}$ are external forces (hydraulic, chemical, and thermal gradients) and $L_{i k}$ are the phenomenological coefficients (coupling coefficients). The self-potential data are therefore a function of the medium electrical resistivity, of the remote thermal, chemical, and hydraulic gradient, and of the coupling coefficient distribution.

Neglecting the thermal contribution, the self-potential source term can be described as the superposition of two components: the so-called electrokinetic and electrochemical potentials.

2.1. Electrokinetic Potential. The electrokinetic potential (or streaming potential) is induced by the motion of electrolytic fluids through porous media. It is generated, in particular, by the flow of the water circulating in the subsoil that, during its path in the interconnected pores, carries with 
it electrical charges present at the mineral/water interface, where it generates a triple electric layer [37-39].

The fluid, under a pressure gradient, flows and carries with it a part of the cations, causing a separation of electric charges at the mineral/water interface. Consequently, an electric field, induced along it, develops, whose potential difference is called $\zeta$ potential.

In particular, in saturated and isothermal conditions, the current density $\left(J_{s}\right)$ is linked to the pressure $(\nabla P)$ and the electric potential $(\nabla V)$ gradients by the coupling equation:

$$
J_{s}=-L_{22} \nabla V-L_{21} \nabla P .
$$

The first term represents Ohm's law, where the coupling coefficient $L_{22}$ is the bulk electrical conductivity $\sigma_{r}\left(\mathrm{~S} \mathrm{~m}^{-1}\right)$, while $L_{21}$ represents the electrokinetic coupling coefficient that is usually experimentally obtained by applying a hydraulic gradient and measuring the resulting electric potential $(\Delta V)$ :

$$
C_{\text {sat }}=-\frac{L_{21}}{\sigma_{r}}=\frac{\Delta P}{\Delta V}=\frac{\zeta \varepsilon_{f}}{\mu_{f} \sigma_{f}},
$$

where $\mu_{f}$ is the electrolyte dynamic viscosity $\left(\mathrm{kg} \mathrm{m}^{-1} \mathrm{~s}^{-1}\right)$, $\varepsilon_{f}$ is the electrolyte dielectric constant $\left(\mathrm{F} \mathrm{m}^{-1}\right), \sigma_{f}$ is the electrolyte electrical conductivity $\left(\mathrm{S} \mathrm{m}^{-1}\right)$, and $\Delta P=\rho_{w} g \Delta h$ is the pressure gradient $(\mathrm{Pa})$ with $\rho_{w}, g$, and $\Delta h$ corresponding to fluid density $\left(\mathrm{kg} \mathrm{m}^{-3}\right)$, gravity acceleration coefficient $\left(\mathrm{m} \mathrm{s}^{-2}\right)$, and hydraulic head $(\mathrm{m})$, respectively.

Considering the modern approach that tries to interpret SP solving coupled problems characterized by a system of linear equations, $J_{s}$ generated by the water flux in the subsoil can be described by [40]:

$$
J_{s}=Q_{v} u,
$$

where $Q_{v}\left(\mathrm{C} \mathrm{m}^{-3}\right)$ is the effective charge per unit pore volume that can be dragged by the flow of the pore water and $u$ is the Darcy velocity $\left(\mathrm{m} \mathrm{s}^{-1}\right)$. Equation (5) is valid also under unsaturated conditions, and, in saturated condition, Revil and Leroy [40] related $Q_{v}$ to the coupling coefficient $C_{\text {sat }}$ $\left(\mathrm{VPa}^{-1}\right)$ through

$$
Q_{v}=-\frac{C_{\text {sat }} \sigma_{f} \mu_{f}}{\rho_{f} g K_{0}},
$$

where $K_{0}$ is the hydraulic conductivity $\left(\mathrm{m} \mathrm{s}^{-1}\right)$. Laboratory measurements suggest that $C_{\text {sat }}$ is mainly dependent by the pore water electrical conductivity $\sigma_{f}$ [41]; moreover, Jardani et al. [42] showed that $Q_{v}$ increases with decreasing hydraulic conductivity.

2.2. Electrochemical Potential. The electrochemical potential was used primarily in the mining exploration because the greatest anomalies of self-potential are generated in correspondence with bodies of pyrite, graphite, or other metallicconductor minerals [43].

Electrochemical sources can be produced by several phenomena. The common ones are the diffusion of ions dissolved in water and the presence of a redox potential. In the last case, the current source $J_{s}$ can be generated by the contaminant biodegradation through microbially mediated redox reactions and can be described by the following equation [23]:

$$
J_{s}=-\sigma_{e} \nabla E_{H},
$$

where $\sigma_{e}$ is the electrical conductivity of an electronically conducting body and $E_{H}$ is the redox potential. This phenomenon is equivalent to the corrosion of two metals in a short-circuited energy-producing cell described by Bockris and Reddy [44]. For this reason, this kind of self-potential source has been defined as "biogeobattery" [23, 45-47].

The absence of strong SP anomalies may be due to the lack of an electron conductor $\left(\sigma_{e}\right.$ in (7)). In this case, the SP signals are explained as diffusion potential [21].

The diffusion potential is another common electrochemical source mechanism caused by the presence of a gradient of the ionic species chemical potential in groundwater. It is described by the following equation:

$$
J_{s}=-k_{b} T \sum_{i=1}^{n} \frac{t_{i}^{ \pm} \sigma_{w}}{q_{i}} \nabla \ln \left\{C_{i}\right\},
$$

where $k_{b}$ is the Boltzmann constant, $T$ is the absolute temperature $(\mathrm{K}), t_{i}^{ \pm}$is the Hittorf transport number of a species $i$ dissolved in water, $q_{i}$ is the charge of the species $i$, and $C_{i}$ is the concentration of ions $\left(\mathrm{g} \mathrm{L}^{-1}\right)$.

The diffusion potential is also called junction potential when an electrical double layer of positive and negative charges is created at the junction of two solutions at different concentration. The more concentrated solution will tend to spread into the less concentrated one, developing a potential difference at the point of connection, due to the ionic transfer. The electrical potential anomaly generated depends on the relative speeds of the ions.

Assume the case of a saturated porous medium where a very small amount of $\mathrm{NaCl}$ solution behaving as a tracer is injected. Ideally, it is possible to neglect the variation of the electrokinetic potential due to the introduction of the $\mathrm{NaCl}$ solution, while the junction potential $(\varphi)$ can be calculated by integrating (8). Therefore, according to Revil [31], Maineult et al. [13, 14], and Martinez-Pagan et al. [3], the measured electrical potential differences $(\Delta \varphi, V)$ inside a moving saline front depend on (Planck-Henderson equation)

$$
\Delta \varphi=-n \frac{K_{b} T}{e}\left(2 t^{+}-1\right) \frac{\nabla C}{C}=n \alpha^{*} \frac{\nabla C}{C},
$$

where $n$ is the porosity, $e$ is the elementary charge of the electron $\left(e=1.602 \times 10^{-19} \mathrm{C}\right), C\left(\mathrm{~g} \mathrm{~L}^{-1}\right)$ represent the solution concentration, and $\alpha^{*}$ is called junction coupling coefficient that, for a $\mathrm{NaCl}$ tracer, is around $5.15 \times 10^{-3} \mathrm{~V}$ [30].

As suggested by Bolève et al. [48] and Crespy et al. [49], (8) and (9) are valid in porous media only for small Dukhin numbers (i.e., the ratio between the surface conductivity of the grains and the pore water electrical conductivity). 


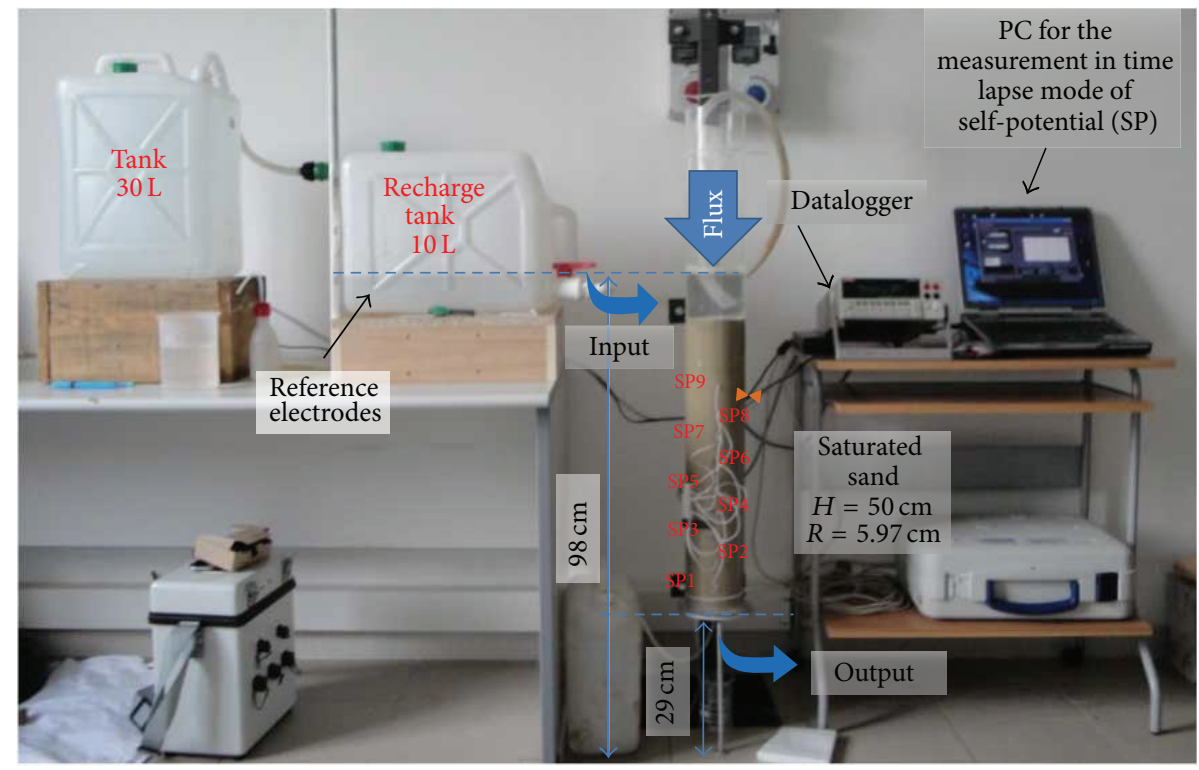

FIGURE 2: Experimental column facility installed at the Hydrogeosite Laboratory of CNR-IMAA (Marsico Nuovo, Italy).

The junction potential term can be obtained by integrating (9):

$$
\varphi=-\frac{\varphi_{0}}{\ln \left(n \alpha^{*}+1\right)} \ln \left(\frac{C_{0}+n \alpha^{*} C}{C_{0}\left(1+n \alpha^{*}\right)}\right)
$$

Therefore, (10) allows us to estimate, starting from electrical potential measurements, the salt solution breakthrough curve at each point, where the junction potential is measured during the experiment:

$$
C=-\frac{C_{0}}{n \alpha^{*}}\left[\left(n \alpha^{*}+1\right)^{\left(\varphi-\varphi_{0}\right) / \varphi_{0}}-1\right] .
$$

Considering one-dimensional flow and transport, the analytical solution of the breakthrough curve is [50] as follows:

$$
\begin{aligned}
\frac{C(x, t)}{C_{0}}= & \frac{1}{2} \operatorname{erfc}\left[\frac{x-\left(u / n_{c}\right) t}{2 \sqrt{D t / n_{c}}}\right] \\
& +\exp \left(\frac{u x}{D}\right) \operatorname{erfc}\left[\frac{x+\left(u / n_{c}\right) t}{2 \sqrt{D t / n_{c}}}\right],
\end{aligned}
$$

where $u$ is Darcy's velocity $\left(\mathrm{m} \mathrm{s}^{-1}\right), n_{c}$ is the kinematic porosity (dimensionless), and $D$ is the dispersion $\left(\mathrm{m}^{2} \mathrm{~s}^{-1}\right)$. In conclusion, (12) allows us to estimate the medium diffusion $(D)$ and dispersivity values $\left(\alpha_{L}\right)$.

\section{Materials and Methods}

3.1. Sand Column Experimental Setup. The aim of this experiment was to use SP method for locating the front of a leaking salt plume during a tracer test experiment and estimating the dispersivity parameters of a porous material.
The experimental setup is shown in Figure 2. The experiment was performed in a $1 \mathrm{~m}$ high Plexiglas column with a radius of about $6 \mathrm{~cm}$. The column is open at the top and close at the bottom where a little hole was done to allow the water outflow. The water level in the column can be controlled by a hydraulic circuit consisting of two tanks connected to the column. This system is also used to keep the recharge rate constant.

The column was partially filled with well-sorted silica sand, saturated by tap water, for a total height of $0.50 \mathrm{~m}$. This sand has been already used in previous hydrogeophysical experiments at the laboratory [51-53] and is characterized by mostly spherical grains, with a diameter ranging from 0.063 to 0.125 , a porosity $n=0.49$, a tortuosity $\tau=0.79$, and a hydraulic conductivity of $5.26 \times 10^{-6} \mathrm{~m} \mathrm{~s}^{-1}$. Moreover, the sand is characterized by an electrical resistivity value of $50 \Omega \mathrm{m}$ (in tap water saturated conditions) and a formation factor $F$ of about 2.62 .

The first step was to fix nine flat nonpolarising $\mathrm{Ag}-\mathrm{AgCl}$ electrodes of $1 \mathrm{~mm}$ diameter (FIAB) along one column side with a spacing of $5 \mathrm{~cm}$. These electrodes used for medical applications (electrocardiogram) have very high performance in terms of noise and voltages offset. Moreover, a reference electrode was put in the first recharge tank, in direct contact with fresh water, and always kept outside the salt plume.

In order to monitor SP signal during the infiltration experiment, all the electrodes were connected to a multichannel voltmeter (2700/EDMM, Keithley Instruments Inc.) and a PC, to collect and visualise the electrical potential differences between column electrodes and the reference one in real time. For the entire experiment, the sand into column was kept saturated; in particular, a hydraulic head of about $0.70 \mathrm{~m}$ was set in order to establish a one-dimensional steady-state flow in the sand $\left(Q=0.35 \mathrm{Lh}^{-1}\right)$. In this way, about 2 litres of 

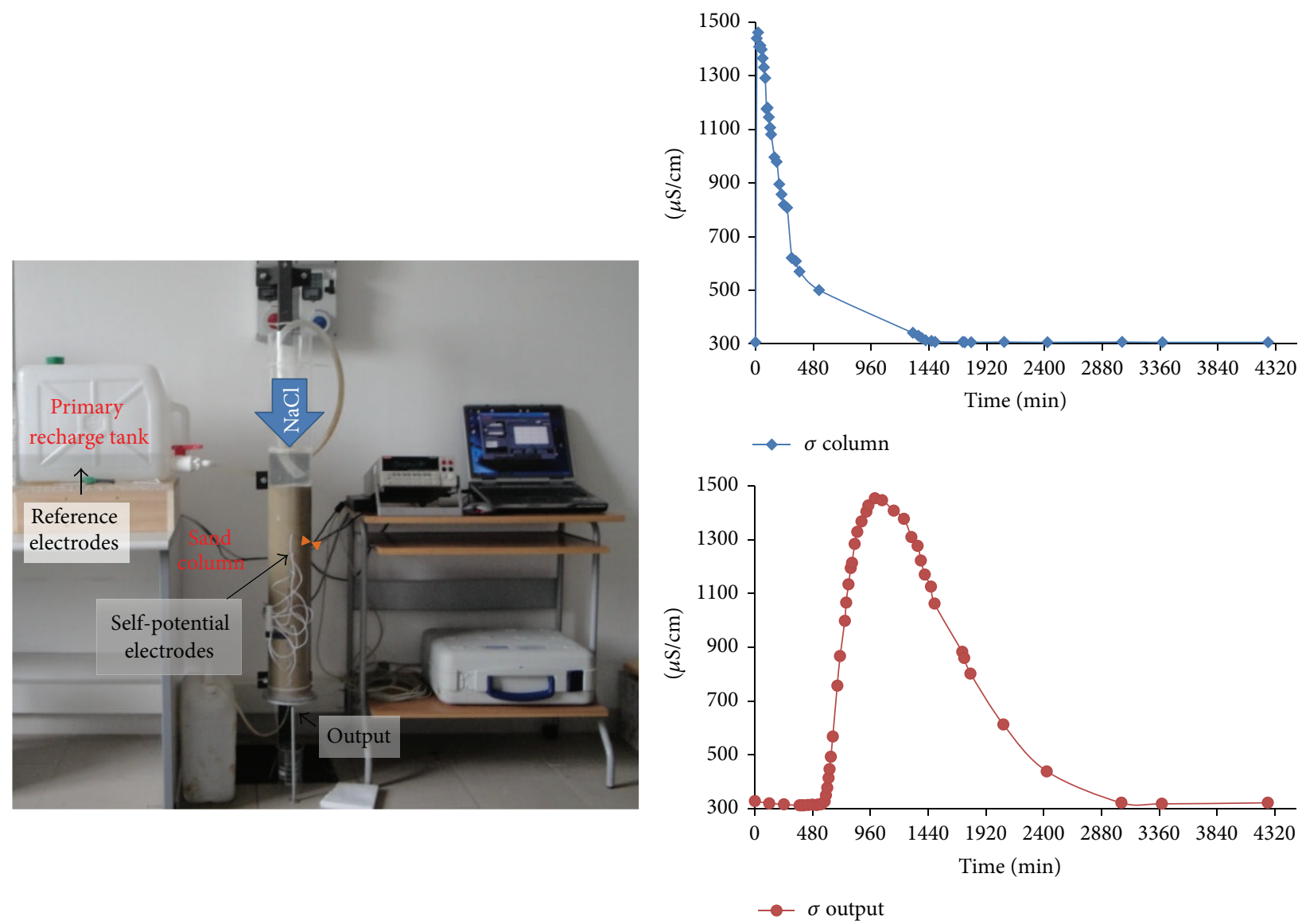

Figure 3: Tracer test experiments: the salt solution was injected at the top of the sand. Water electrical conductivity, monitored both in the column and at the output, shows the tracer behaviour during the test.

water remained above the sand body. After the steady-state flow was created, the voltage difference for each electrode was measured every 10 minutes for one day in order to set up a background baseline and noise level for the used geophysical method (characterization experimental phase).

3.2. Tracer Test Monitoring by SP. One day after steady-state flow was created, a salt solution of tap water and $\mathrm{NaCl}$ was injected at the top of the sand; in this way, the salt water began to migrate in the column by advection and diffusion. Three experimental phases were performed with a diminishing amount of salt concentration by injecting small volumes of salt solution into the system in order to make steady-state flow disturbances negligible. During the three experiments, the SP signals and the solution concentration were monitored every 1 and 15 minutes, respectively. The water electrical conductivity was measured both in the column and in a small box at the column end (output box) where the spreading solutions were collected (Figure 3 ).

The experiments lasted about 40 hours which was a time long enough to observe the return of normal conditions of water electrical conductivity in the output box.

The first experimental phase consisted in the monitoring by self-potential measurements of the saline front movement after the injection of $6.00 \mathrm{~g} \mathrm{~L}^{-1} \mathrm{NaCl}$ solution at the top of the column. When this salt solution was injected up to the sand body, the water was mixed to the tap water in order to ensure a homogeneous input concentration. These actions required less than 15 seconds; therefore, we can approximate the solution injection as a pulse. Few minutes after the injection, the electrical conductivity of water suddenly increased from 312 to $1455 \mu \mathrm{S} \mathrm{cm}^{-1}$ (normalized at $20^{\circ} \mathrm{C}$ ) and then quickly reduced its values as the effect of the migration of salt solution and the inflow of tap water from the recharge tanks.

The second experimental phase consisted in the monitoring by SP of the saline front movement after the injection of $1.00 \mathrm{~g} \mathrm{~L}^{-1} \mathrm{NaCl}$ solution. In this case, when this salt solution was injected, the electrical conductivity of water increased from 295 to $458 \mu \mathrm{S} \mathrm{cm}^{-1}$ (normalized at $20^{\circ} \mathrm{C}$ ).

Finally, the third experimental phase consisted in monitoring by SP the saline front movement after the injection of $0.25 \mathrm{~g} \mathrm{~L}^{-1} \mathrm{NaCl}$ solution. In this last experimental phase, after the salt solution injection, the electrical conductivity of water recorded a small variation from 308 to $343 \mu \mathrm{S} \mathrm{cm}^{-1}$ (normalized at $20^{\circ} \mathrm{C}$ ). Converting water electrical conductivity into solution concentration, it was possible to monitor the input salt concentrations evolution at the top of the column during the three experiments (Figure 4). 


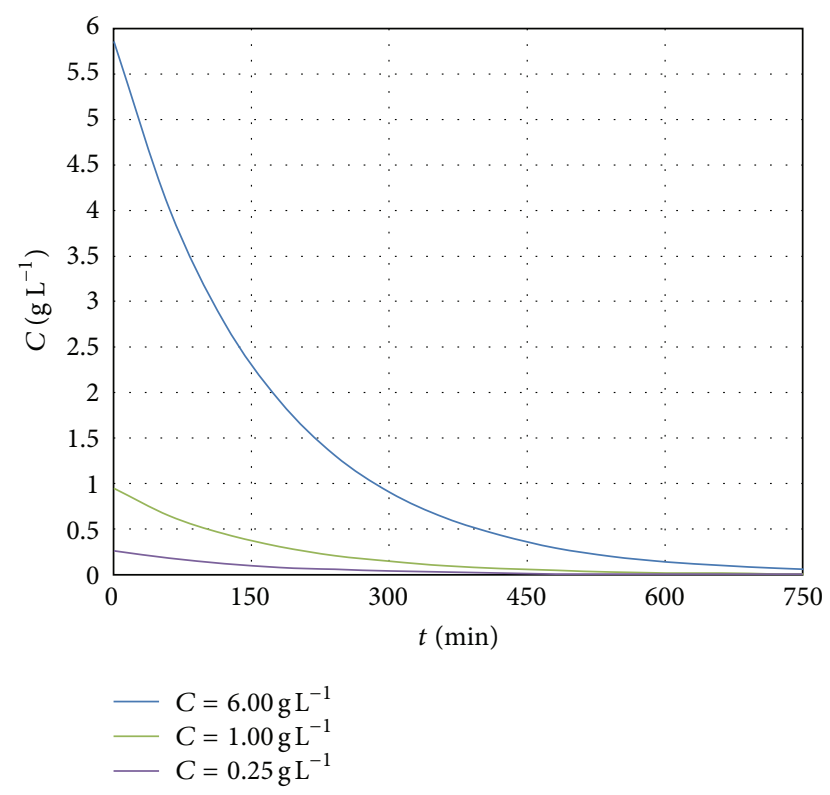

FIGURE 4: Input salt concentration measured at the top of the column during the experiment.

\section{Results and Discussion}

Figure 5 shows the SP values, acquired during the tracer test, at different salt solution concentration, while Figure 6 shows the comparison between SP values measured at different salt solution concentration (blue $=6.00 \mathrm{~g} \mathrm{~L}^{-1}$, green $=1.00 \mathrm{~g} \mathrm{~L}^{-1}$, and violet $=0.25 \mathrm{~g} \mathrm{~L}^{-1}$ ), at three different positions of the column. SP data have been corrected taking into account SP signals measured during the characterization experimental phase.

In particular, analysing SP measured values, it is possible to observe that (1) all electrodes measured a sharp reduction of the SP signal, in correspondence with the saline front passage; (2) this phenomenon is more rapid with the diminishing concentration of injected solution; and (3) the absolute values of SP anomaly increase with increasing amount of $\mathrm{NaCl}$ solution added to the system, where the greater negative measured SP anomalies were about $-78.99 \pm$ $3.24 \mathrm{mV}$ for the salt concentration of $6.00 \mathrm{~g} \mathrm{~L}^{-1},-54.52 \pm$ $2.28 \mathrm{mV}$ for the salt concentration of $1.00 \mathrm{~g} \mathrm{~L}^{-1}$, and $-24.12 \pm$ 1.21 for the salt concentration of $0.25 \mathrm{~g} \mathrm{~L}^{-1}$. During the last experimental phase, the electrode SP8 measured very low SP values $(-5 \mathrm{mV})$ with a great noise level; therefore, it is not considered in the following discussions.

Moreover, analysing the response of SP electrodes, it is possible to see that, in all experimental phases, the SP3 electrode reacts to the salt passage with some delay; therefore, also in this case SP3 was not considered.

The salt front took about $21 \mathrm{~min}$ to reach the first electrodes (SP9). The average travel time of the salt front at each electrode resulted to be $39.22,32.33$, and $29.67 \mathrm{~min}$ with an error of $\pm 1.27 \mathrm{~min}$, for salt concentrations of $6.00,1.00$, and $0.25 \mathrm{~g} \mathrm{~L}^{-1}$, respectively.
TABLE 1: Hydrogeophysical input parameter for the simulation.

\begin{tabular}{lc}
\hline Parameters & Values \\
\hline Hydraulic permeability $K$ & $5.26 e-6\left(\mathrm{~m} \mathrm{~s}^{-1}\right)$ \\
Porosity $\theta$ & 0.49 (dimensionless) \\
Dispersivity & $1 e-3(\mathrm{~m})$ \\
Diffusion coefficient & $1-9\left(\mathrm{~m}^{2} \mathrm{~s}^{-1}\right)$ \\
Tortuosity factor & 0.79 (dimensionless) \\
\hline
\end{tabular}

For a one-dimensional flow configuration, the salt front average velocity at each electrode can be calculated, for the different salt concentration, knowing the average travel time. The average flow velocities were estimated to be $1.3,1.5$, and $1.7 \mathrm{~mm} \mathrm{~min}^{-1}$ with an error of $\pm 0.2 \mathrm{~mm} \mathrm{~min}^{-1}$, for the 6.00 , 1.00 , and $0.25 \mathrm{~g} \mathrm{~L}^{-1}$ concentrations, respectively.

4.1. SP Modelling. In order to estimate sand dispersivity parameters and determine the flow pathway of the salt solution and its concentration changes inside the column, a hydrogeophysical inversion approach has been used. In particular, self-potential measurements were transformed in salt concentration values using (11) and then concentration values were optimized to obtain transport parameters (see (12)). Figure 7 shows concentration curves obtained from SP data at different time instants and heights in the column.

Both the forward finite element model and the inversion were performed with COMSOL Multiphysics $4.3 \mathrm{~b}$, a multiphysics software tool for the solution of partial differential equations (PDEs), which is based on the finite element method. Physical properties used in the starting forward model are assumed to be constant throughout the entire solution domain and are summarized in Table 1.

The sand column is fully saturated and a water flux was created. The system physical conditions allowed us to use the module Fluid Flow $\rightarrow$ Porous Media and Saturated Flow $\rightarrow$ Darcy's Law $\rightarrow$ Stationary conditions to estimate Darcy's velocity field that was characterized by $u=v_{x}=0, v=v_{y}=0$, and $w=v_{z} \neq 0$.

Because the salt solution travels through the column according to the advection-dispersion equation, the Fluid Flow module wascoupled to the module Chemical Species Transport $\rightarrow$ Solute transport $\rightarrow$ Time depending conditions. Moreover, in order to perform the optimization of transport parameters the Optimization module has been further added to the simulation. The entire $3 \mathrm{D}$ domain was discretized in 1247 domain tetrahedral elements.

In the case of a pulse tracer injection from the top, the boundary condition at the top of the column $(x=0.5 \mathrm{~m})$ is that, (1) for $t_{0}=0 \mathrm{~s}$, the concentration $C$ is null $\left(C_{0}=0\right)$, and the hydraulic head is $H=0.70 \mathrm{~m}$, while (2) at the time $t_{i}$, $H$ remains constant due to the low concentrations of solute introduced.

Moreover, considering the salt solution small amount injected, it is possible to neglect the effect of salt concentration upon dynamic viscosity and mass density of the pore water. 


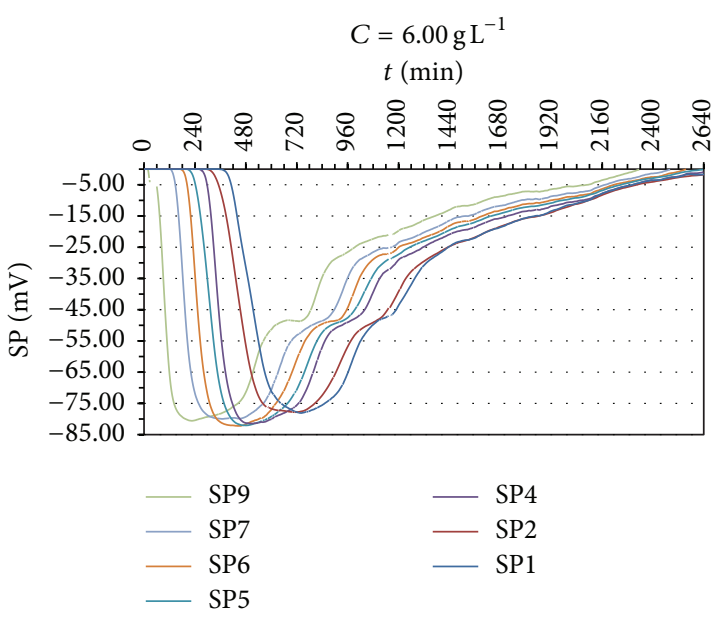

(a)

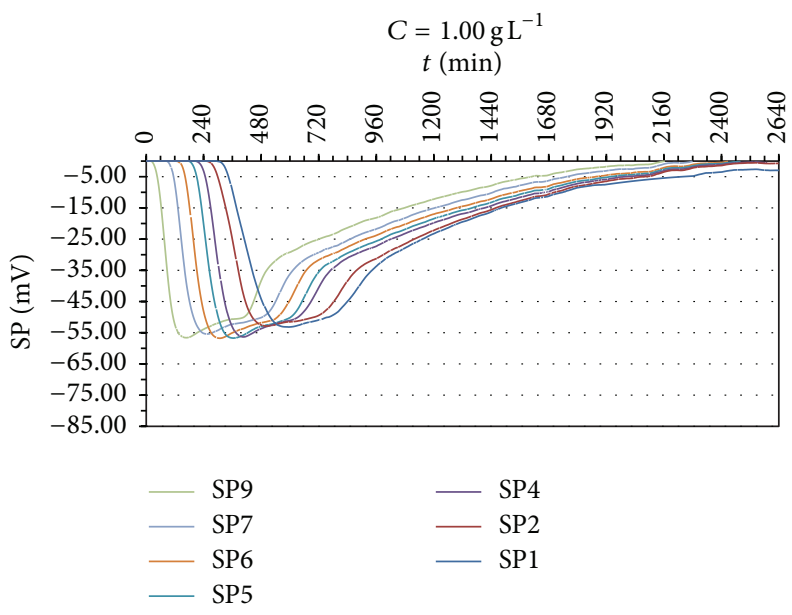

(b)

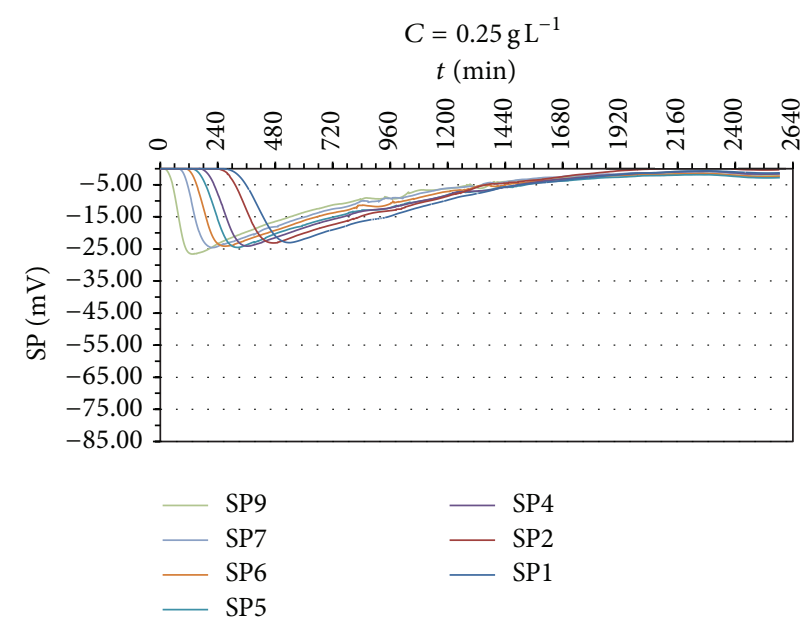

(c)

FIGURE 5: SP data measured during the tracer test with a salt concentration of (a) $6.00 \mathrm{~g} \mathrm{~L}^{-1}$, (b) $1.00 \mathrm{~g} \mathrm{~L}^{-1}$, and (c) $0.25 \mathrm{~g} \mathrm{~L}^{-1}$.

On the contrary, the boundary condition at the bottom of the column $(x=0 \mathrm{~m})$ is atmosphere/gauge for the Fluid Flow module and outflow for the Solute transport one. Finally, the sides boundaries are characterized by no flow and no flux conditions.

The input parameters for the Optimization module are constituted by salt breakthrough curves inside the column during all the experiments estimated starting from measured SP measurements (Figure 7). On the contrary, the terms $D$ and $\alpha_{L}$ (diffusion and dispersion) represent the parameters to optimize because they mostly influence the variation of the saline concentrations in the investigated medium. The dispersion tensor is constituted by the linear terms $\alpha_{x}=$ alpha $L ; \alpha_{y}=$ alpha $L / 10$; and $\alpha_{z}=$ alpha $L / 10$. In particular, the nonlinear last square Nelder-Mead optimization method was chosen.

Figure 8 shows the results of the inversion obtained by COMSOL Multiphysics of the saline trace test in the column (input salt concentration of $6.00 \mathrm{~g} \mathrm{~L}^{-1}$ ), where the solution concentration inside the sand body reaches the maximum values just after the injection and then decreases during time. The values of $D$ and $\alpha_{L}$, determined for all three experiments, are shown in Table 2. The diffusion and longitudinal dispersivity values estimated are comparable with fine sands typical ones measured in laboratory [13, 30].

For each experiment, Figure 9 shows a comparison between the $\mathrm{NaCl}$ concentrations calculated by (11), starting from the electrical potential differences measured by SP electrodes, and those modelled by the COMSOL Multiphysics inverse procedure. These results confirm the validity of the model, showing a good agreement between the modelled and observed $\mathrm{NaCl}$ concentrations.

\section{Conclusions}

At the Hydrogeosite Laboratory of CNR-IMAA, a controlled diffusion/infiltration sand column experimental activity was 

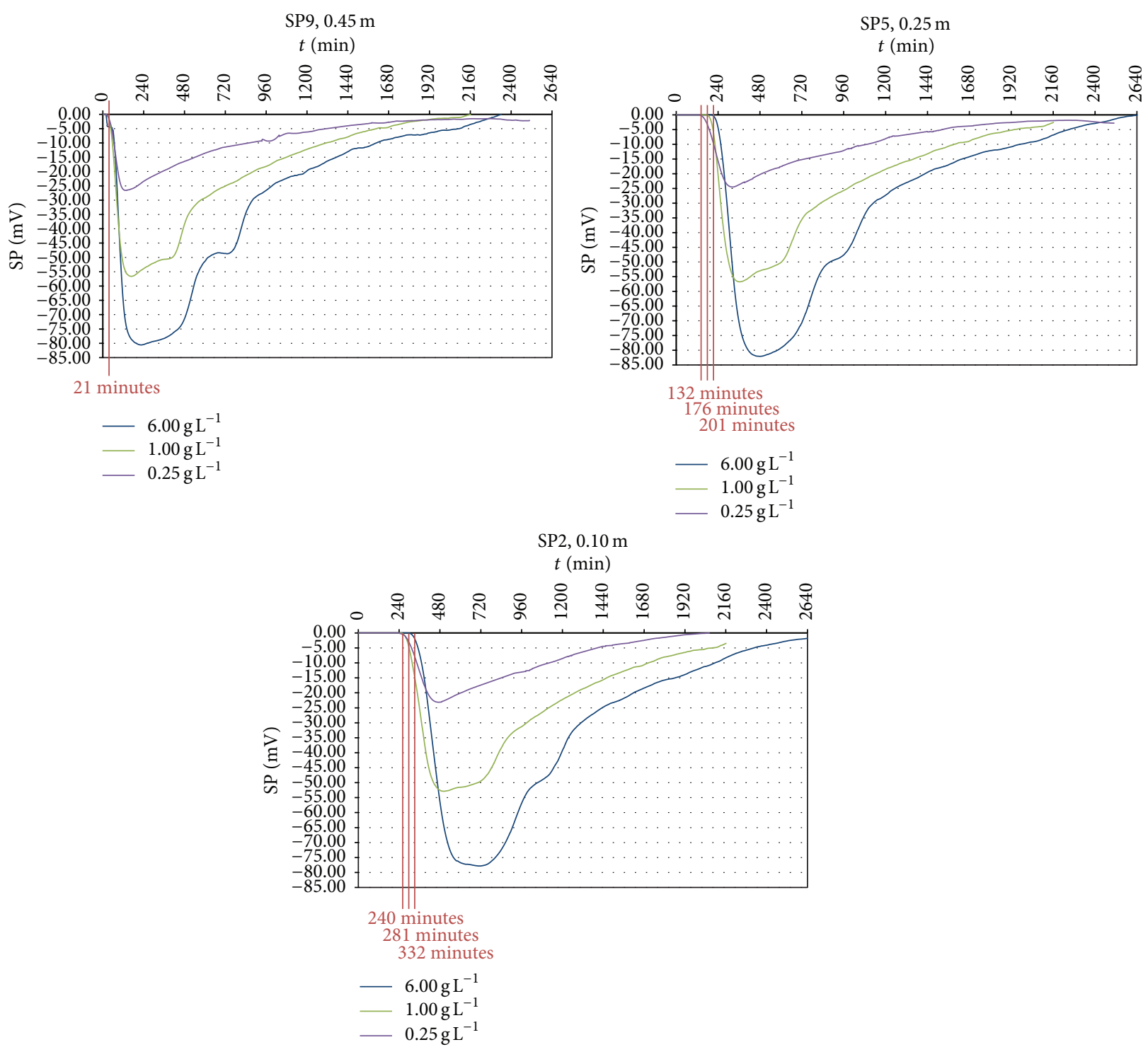

FIGURE 6: Comparison between SP values measured at different salt solution concentration (blue $=6.00 \mathrm{~g} \mathrm{~L}^{-1}$, green $=1.00 \mathrm{~g} \mathrm{~L}^{-1}$, and violet $=$ $\left.0.25 \mathrm{~g} \mathrm{~L}^{-1}\right)$, at three different positions of the column. The red lines indicate the arrival time of the saline front at the electrodes.

TABLE 2: Values of diffusion and longitudinal dispersivity calculated using self-potential signals registered at each electrode along the column using a hydrogeophysical inversion approach.

\begin{tabular}{lccc}
\hline Tracer test & $D\left(\mathrm{~m}^{2} \mathrm{~s}^{-1}\right)$ & $\alpha_{L}(\mathrm{~m})$ & $R^{2}$ \\
\hline $6.00\left(\mathrm{~kg} \mathrm{~m}^{-3}\right)$ & $1 e-8.95$ & 0.00186 & 0.986 \\
$0.95\left(\mathrm{~kg} \mathrm{~m}^{-3}\right)$ & $1 e-8.95$ & 0.00128 & 0.985 \\
$0.26\left(\mathrm{~kg} \mathrm{~m}^{-3}\right)$ & $1 e-9.03$ & 0.00114 & 0.984 \\
\hline
\end{tabular}

carried out with the aim of monitoring the leakage of a plume of salty water using time-lapse self-potential measurements.

In particular, three pulse input tracer tests were monitored by SP and the diffusion and the dispersivity parameters of the porous material were estimated applying a hydrogeophysical inversion approach.
The salt plume movement inside the column generated clear negative self-potential anomalies; in fact, all electrodes showed a sharp reduction in the measured SP signal, in correspondence with the saline front passage. In particular, this phenomenon is more rapid with the diminishing concentration of injected solution, while the absolute values of $\mathrm{SP}$ anomaly increase with increasing $\mathrm{NaCl}$ solution added to the system.

These measured self-potential anomalies were produced by the combination of the streaming potential, due to the pore water flow, and the diffusion potential linked to the ions chemical potential gradients in groundwater. Moreover, due to the low concentrations of solute introduced into the system, we assumed that the electrokinetic effect linked to the injection of the $\mathrm{NaCl}$ solution was negligible.

Self-potential measurements have been used to obtain diffusion $\left(D, \mathrm{~m}^{2} \mathrm{~s}^{-1}\right)$ and longitudinal dispersivity $\left(\alpha_{L}, \mathrm{~m}\right)$ 

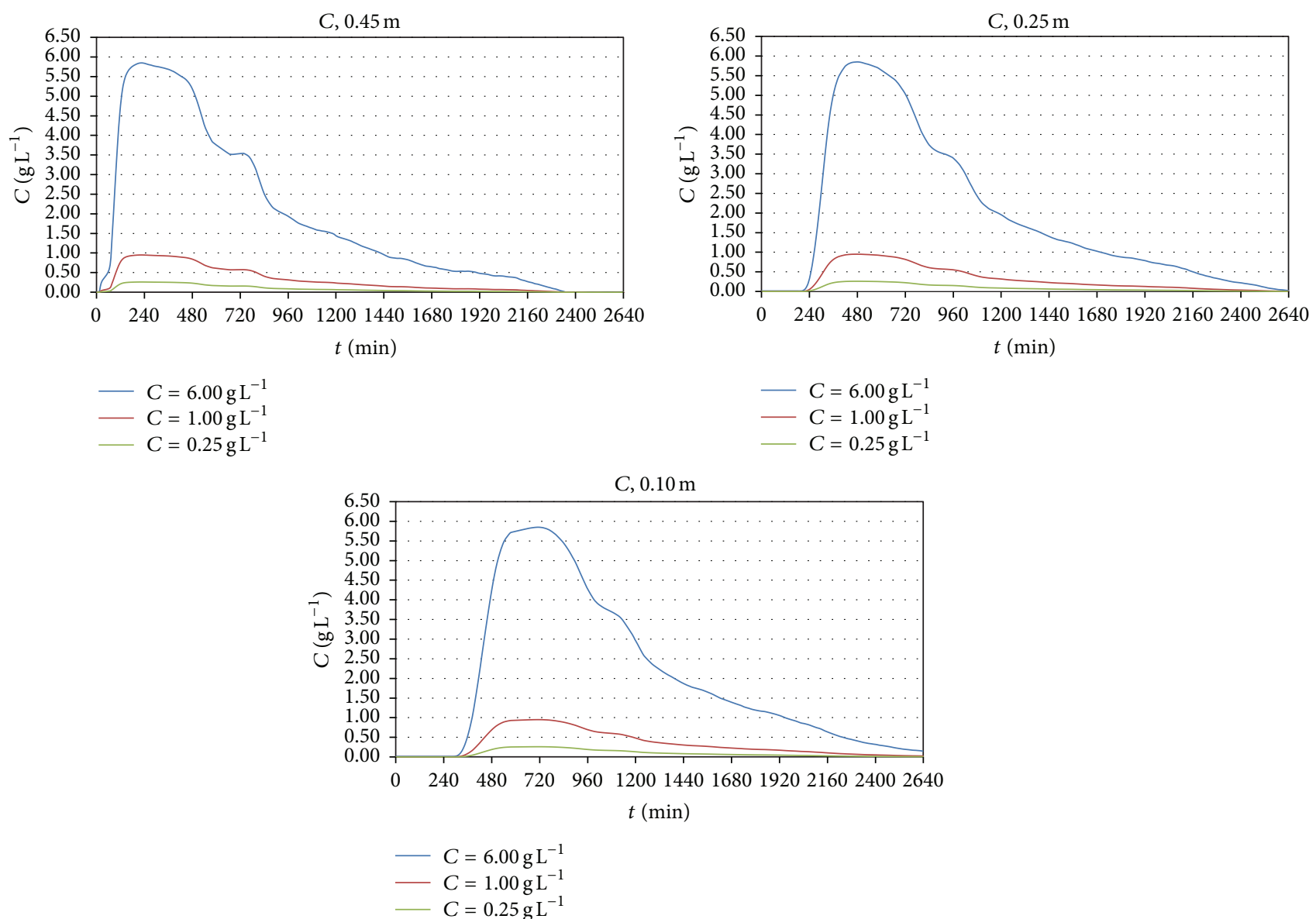

Figure 7: Salt concentration obtained by the measured SP signals at three different positions of the column.
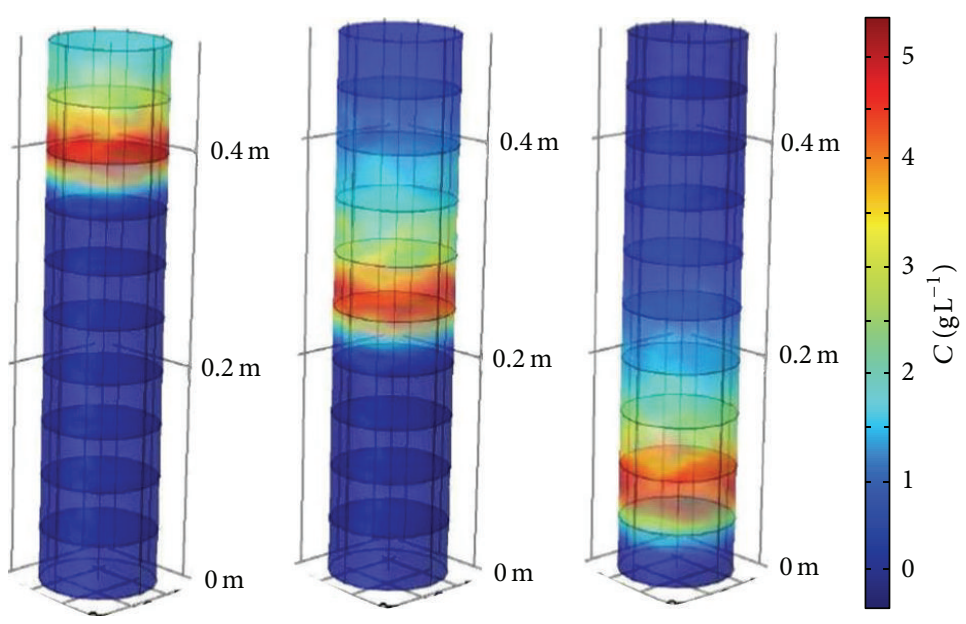

FIGURE 8: Simulation of a saline trace test in the column water flow by COMSOL Multiphysics.

firstly converting electrical potential values $(\mathrm{mV})$ into concentration values $\left(\mathrm{g} \mathrm{L}^{-1}\right)$ by the Planck-Henderson equation and then calculating the transport parameters by the equations implemented in the COMSOL Multiphysics environment.
This paper shows the capability of self-potential as a cheap tool to detect contaminants at very low concentrations. Moreover, the use of the SP data allows us to define and optimize the physical parameters of the model that simulates the distribution of the contaminant in the simulated aquifer. 


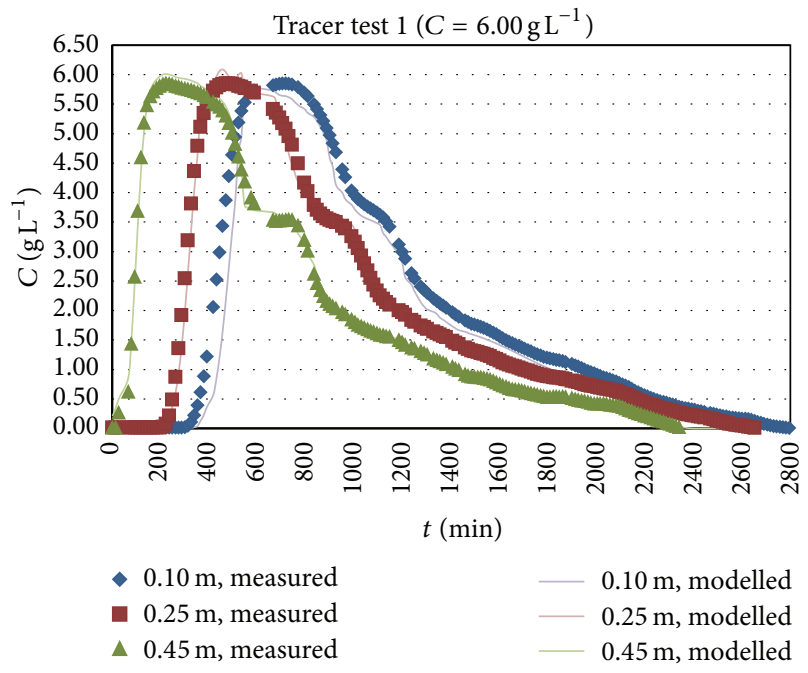

(a)

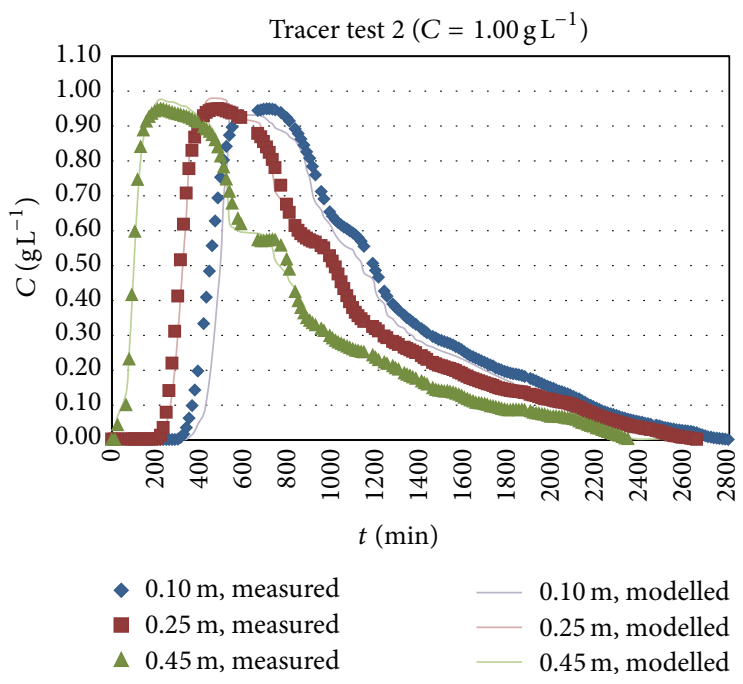

(b)

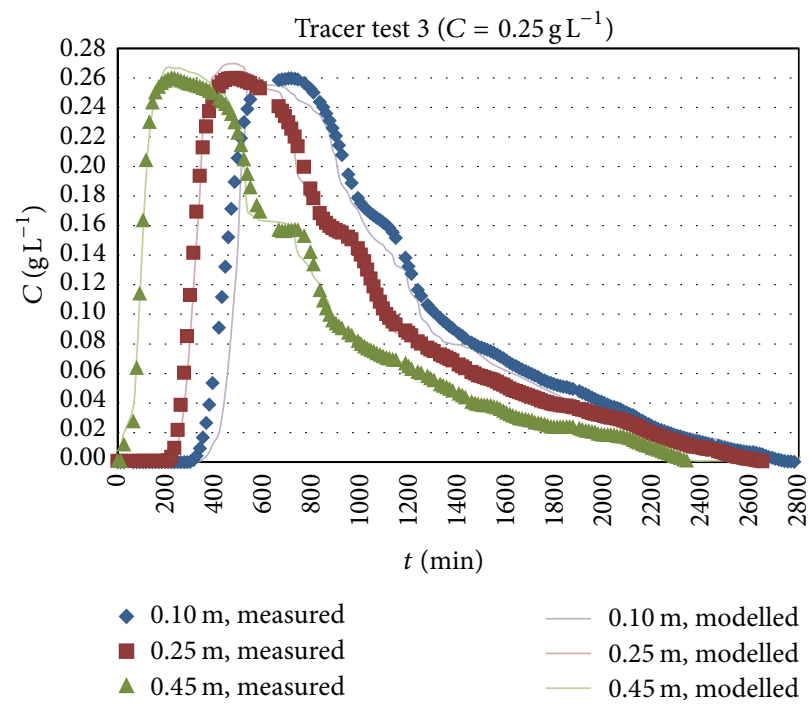

(c)

Figure 9: Comparison between breakthrough curves obtained from self-potential signals (dots) and those calculated by inversion (lines) for the tracer test with a salt concentration of (a) $6.00 \mathrm{~g} \mathrm{~L}^{-1}$, (b) $1.00 \mathrm{~g} \mathrm{~L}^{-1}$, and (c) $0.25 \mathrm{~g} \mathrm{~L}^{-1}$.

More field work of this nature is necessary to validate the usefulness of self-potential in real heterogeneous conditions with limited hydrological data.

\section{Conflict of Interests}

The authors declare that there is no conflict of interests regarding the publication of this paper.

\section{Acknowledgment}

This research has been performed in the frame of the Ticamosc Project "Tecnologie Idrogeofisiche per la Caratterizzazione ed il Monitoraggio di Siti Contaminati" funded by a PO FSE Basilicata 2007-2013: "Promozione della Ricerca e dell'Innovazione e Sviluppo di Relazioni con il
Sistema Produttivo Regionale” DD no. 796/2013, Azione no. 19/AP/05/2013/REG.

\section{References}

[1] L. Slater, A. Binley, R. Versteeg, G. Cassiani, R. Birken, and S. Sandberg, "A 3D ERT study of solute transport in a large experimental tank," Journal of Applied Geophysics, vol. 49, no. 4, pp. 211-229, 2002.

[2] A. Binley, G. Cassiani, R. Middleton, and P. Winship, "Vadose zone flow model parameterisation using cross-borehole radar and resistivity imaging," Journal of Hydrology, vol. 267, no. 3-4, pp. 147-159, 2002.

[3] P. Martínez-Pagán, A. Jardani, A. Revil, and A. Haas, "Selfpotential monitoring of a salt plume," Geophysics, vol. 75, no. 4, pp. 17-25, 2010. 
[4] A. Bolève, F. Janod, A. Revil, A. Lafon, and J.-J. Fry, "Localization and quantification of leakages in dams using timelapse self-potential measurements associated with salt tracer injection," Journal of Hydrology, vol. 403, no. 3-4, pp. 242-252, 2011.

[5] W. R. Sill, "Self-potential modeling from primary flows," Geophysics, vol. 48, no. 1, pp. 76-86, 1983.

[6] Y. Bernabé, "Streaming potential in heterogeneous networks," Journal of Geophysical Research: Solid Earth, vol. 103, no. 9, pp. 20827-20841, 1998.

[7] A. Revil, P. A. Pezard, and P. W. J. Glover, "Streaming potential in porous media: 1 . Theory of the zeta potential," Journal of Geophysical Research: Solid Earth, vol. 104, no. 9, pp. 2002120031, 1999.

[8] A. Revil, H. Schwaeger, L. M. Cathles III, and P. D. Manhardt, "Streaming potential in porous media. 2. Theory and application to geothermal systems," Journal of Geophysical Research: Solid Earth, vol. 104, no. 9, Article ID 1999JB900090, pp. 2003320048, 1999.

[9] E. Rizzo, B. Suski, A. Revil, S. Straface, and S. Troisi, "Selfpotential signals associated with pumping tests experiments," Journal of Geophysical Research B: Solid Earth, vol. 109, no. 10, Article ID B10203, 2004.

[10] E. A. Atekwana, E. Atekwana, F. D. Legall, and R. V. Krishnamurthy, "Field evidence for geophysical detection of subsurface zones of enhanced microbial activity," Geophysical Research Letters, vol. 31, no. 23, pp. 1-5, 2004.

[11] E. A. Atekwana, E. A. Atekwana, D. D. Werkema et al., "Evidence for microbial enhanced electrical conductivity in hydrocarbon-contaminated sediments," Geophysical Research Letters, vol. 31, no. 23, Article ID L23501, 2004.

[12] V. Naudet and A. Revil, "A sandbox experiment to investigate bacteria-mediated redox processes on self-potential signals," Geophysical Research Letters, vol. 32, no. 11, Article ID L11405, 4 pages, 2005.

[13] A. Maineult, Y. Bernabé, and P. Ackerer, "Detection of advected concentration and $\mathrm{pH}$ fronts from self-potential measurements," Journal of Geophysical Research: Solid Earth, vol. 110, no. 11, Article ID B11205, 2005.

[14] A. Maineult, L. Jouniaux, and Y. Bernabé, "Influence of the mineralogical composition on the self-potential response to advection of $\mathrm{KCl}$ concentration fronts through sand," Geophysical Research Letters, vol. 33, no. 24, Article ID L24311, 2006.

[15] A. Revil and N. Linde, "Chemico-electromechanical coupling in microporous media," Journal of Colloid and Interface Science, vol. 302, no. 2, pp. 682-694, 2006.

[16] T. Arora, N. Linde, A. Revil, and J. Castermant, "Non-intrusive characterization of the redox potential of landfill leachate plumes from self-potential data," Journal of Contaminant Hydrology, vol. 92, no. 3-4, pp. 274-292, 2007.

[17] B. J. Minsley, J. Sogade, and F. D. Morgan, “Three-dimensional self-potential inversion for subsurface DNAPL contaminant detection at the Savannah River Site, South Carolina," Water Resources Research, vol. 43, no. 4, Article ID W04429, 2007.

[18] B. J. Minsley, J. Sogade, and F. D. Morgan, "Three-dimensional source inversion of self-potential data," Journal of Geophysical Research: Solid Earth, vol. 112, no. 2, Article ID B02202, 2007.

[19] C. A. Mendonça, "Forward and inverse self-potential modeling in mineral exploration," Geophysics, vol. 73, no. 1, pp. F33-F43, 2008.
[20] L. Jouniaux, A. Maineult, V. Naudet, M. Pessel, and P. Sailhac, "Review of self-potential methods in hydrogeophysics," Comptes Rendus Geoscience, vol. 341, no. 10-11, pp. 928-936, 2009.

[21] A. Revil, F. Trolard, G. Bourrié, J. Castermant, A. Jardani, and C. A. Mendonça, "Ionic contribution to the self-potential signals associated with a redox front," Journal of Contaminant Hydrology, vol. 109, no. 1-4, pp. 27-39, 2009.

[22] E. A. Atekwana and E. A. Atekwana, "Geophysical signatures of microbial activity at hydrocarbon contaminated sites: a review," Surveys in Geophysics, vol. 31, no. 2, pp. 247-283, 2010.

[23] A. Revil, C. A. Mendonça, E. A. Atekwana, B. Kulessa, S. S. Hubbard, and K. J. Bohlen, "Understanding biogeobatteries: where geophysics meets microbiology," Journal of Geophysical Research, vol. 115, Article ID G00G02, 2010.

[24] A. A. Ogilvy, M. A. Ayed, and V. A. Bogoslovsky, "Geophysical studies of water leakages from reservoirs," Geophysical Prospecting, vol. 17, no. 1, pp. 36-62, 1969.

[25] F. Perrier, M. Trique, B. Lorne, J.-P. Avouac, S. Hautot, and P. Tarits, "Electric potential variations associated with yearly lake level variations," Geophysical Research Letters, vol. 25, no. 10, pp. 1955-1958, 1998.

[26] M. Trique, F. Perrier, T. Froidefond, J. Avouac, and S. Hautot, "Fluid flow near reservoir lakes inferred from the spatial and temporal analysis of the electric potential," Journal of Geophysical Research B: Solid Earth, vol. 107, no. 10, p. 2239, 2002.

[27] A. Revil, D. Hermitte, M. Voltz et al., "Self-potential signals associated with variations of the hydraulic head during an infiltration experiment," Geophysical Research Letters, vol. 29, no. 7, pp. 101-104, 2002.

[28] K. Titov, Y. Ilyin, P. Konosavski, and A. Levitski, "Electrokinetic spontaneous polarization in porous media: petrophysics and numerical modelling," Journal of Hydrology, vol. 267, no. 3-4, pp. 207-216, 2002.

[29] A. Maineult, Y. Bernabé, and P. Ackerer, "Electrical response of flow, diffusion, and advection in a laboratory sand box," Vadose Zone Journal, vol. 3, no. 4, pp. 1180-1192, 2004.

[30] A. Revil and A. Jardani, "Stochastic inversion of permeability and dispersivities from time lapse self-potential measurements: a controlled sandbox study," Geophysical Research Letters, vol. 37, no. 11, Article ID L11404, 2010.

[31] A. Revil, "Ionic diffusivity, electrical conductivity, membrane and thermoelectric potentials in colloids and granular porous media: a unified model," Journal of Colloid and Interface Science, vol. 212, no. 2, pp. 503-522, 1999.

[32] S. J. Ikard, A. Revil, A. Jardani, W. F. Woodruff, M. Parekh, and M. Mooney, "Saline pulse test monitoring with the self-potential method to nonintrusively determine the velocity of the pore water in leaking areas of earth dams and embankments," Water Resources Research, vol. 48, no. 4, 2012.

[33] V. Giampaolo, E. Rizzo, K. Titov et al., "Self-potential monitoring of a crude oil-contaminated site (Trecate, Italy)," Environmental Science and Pollution Research, vol. 21, no. 15, pp. 89328947, 2014.

[34] V. Lapenna, K. Binieris, E. Rizzo et al., "New prototype for 4D self-potential tomography in near-surface geophysical exploration," in Subsurface Sensing Technologies and Applications II, C. Nyguyen, Ed., vol. 4129 of Proceedings of SPIE, pp. 447-456, San Diego, Calif, USA, July 2000.

[35] L. Onsager, "Reciprocal relations in irreversible processes. I.," Physical Review Letters, vol. 37, no. 4, pp. 405-426, 1931. 
[36] B. Nourbehecht, Irreversible thermodynamic effects in inhomogeneous media and their applications in certain geoelectric problems [Ph.D. thesis], Massachusetts Institute of Technology, Cambridge, Mass, USA, 1963.

[37] D. G. Grahame, "The electrical double layer and the theory of electrocapillarity," Chemical Reviews, vol. 41, no. 3, pp. 441-501, 1947.

[38] J. A. Davis, R. O. James, and J. O. Leckie, "Surface ionization and complexation at the oxide/water interface," Journal of Colloid and Interface Science, vol. 63, no. 3, pp. 480-499, 1978.

[39] A. Revil, V. Naudet, J. Nouzaret, and M. Pessel, "Principles of electrography applied to self-potential electrokinetic sources and hydrogeological applications," Water Resources Research, vol. 39, no. 5, pp. SBH31-SBH315, 2003.

[40] A. Revil and P. Leroy, "Constitutive equations for ionic transport in porous shales," Journal of Geophysical Research B: Solid Earth, vol. 109, no. 3, Article ID B03208, 2004.

[41] B. Suski, A. Revil, K. Titov et al., "Monitoring of an infiltration experiment using the self-potential method," Water Resources Research, vol. 42, no. 8, Article ID W08418, 2006.

[42] A. Jardani, A. Revil, A. Bolève, J. P. Dupont, W. Barrash, and B. Malama, "Tomography of groundwater flow from self-potential (SP) data," Geophysical Research Letters, vol. 34, Article ID L24403, 2007.

[43] M. Sato and H. M. Mooney, "The electrochemical mechanism of sulphide self-potentials," Geophysics, vol. 25, no. 1, pp. 226-249, 1960.

[44] J. Bockris and A. K. N. Reddy, Modern Electrochemistry, Plenum Press, New York, NY, USA, 2000.

[45] J. Bigalke and E. W. Grabner, "The Geobattery model: a contribution to large scale electrochemistry," Electrochimica Acta, vol. 42, no. 23-24, pp. 3443-3452, 1997.

[46] F. Timm and P. Möller, "The relation between electric and redox potential: evidence from laboratory and field measurements," Journal of Geochemical Exploration, vol. 72, no. 2, pp. 115-128, 2001.

[47] V. Naudet, A. Revil, E. Rizzo, J.-Y. Bottero, and P. Bégassat, "Groundwater redox conditions and conductivity in a contaminant plume from geoelectrical investigations," Hydrology and Earth System Sciences, vol. 8, no. 1, pp. 8-22, 2004.

[48] A. Bolève, A. Crespy, A. Revil, F. Janod, and J. L. Mattiuzzo, "Streaming potentials of granular media: influence of the Dukhin and Reynolds numbers," Journal of Geophysical Research: Solid Earth, vol. 112, no. 8, Article ID B08204, 2007.

[49] A. Crespy, A. Bolève, and A. Revil, "Influence of the Dukhin and Reynolds numbers on the apparent zeta potential of granular porous media," Journal of Colloid and Interface Science, vol. 305, no. 1, pp. 188-194, 2007.

[50] J. Bear, Hydraulics of Groundwater, McGraw-Hill, New York, NY, USA, 1979.

[51] S. Straface, E. Rizzo, and F. Chidichimo, "Estimation of hydraulic conductivity and water table map in a large-scale laboratory model by means of the self-potential method," Journal of Geophysical Research: Solid Earth, vol. 115, no. 6, Article ID B06105, pp. 1-18, 2010.

[52] S. Straface, E. Rizzo, V. Giampaolo, and F. Chidichimo, "Estimation of hydraulic conductivity in a large scale laboratory model by means of the self-potential method," International Water Technology Journal, vol. 1, no. 1, pp. 24-36, 2011.

[53] F. Chidichimo, M. De Biase, E. Rizzo, S. Masi, and S. Straface, "Hydrodynamic parameters estimation from self-potential data in a controlled full scale site," Journal of Hydrology, vol. 522, pp. 572-581, 2015. 

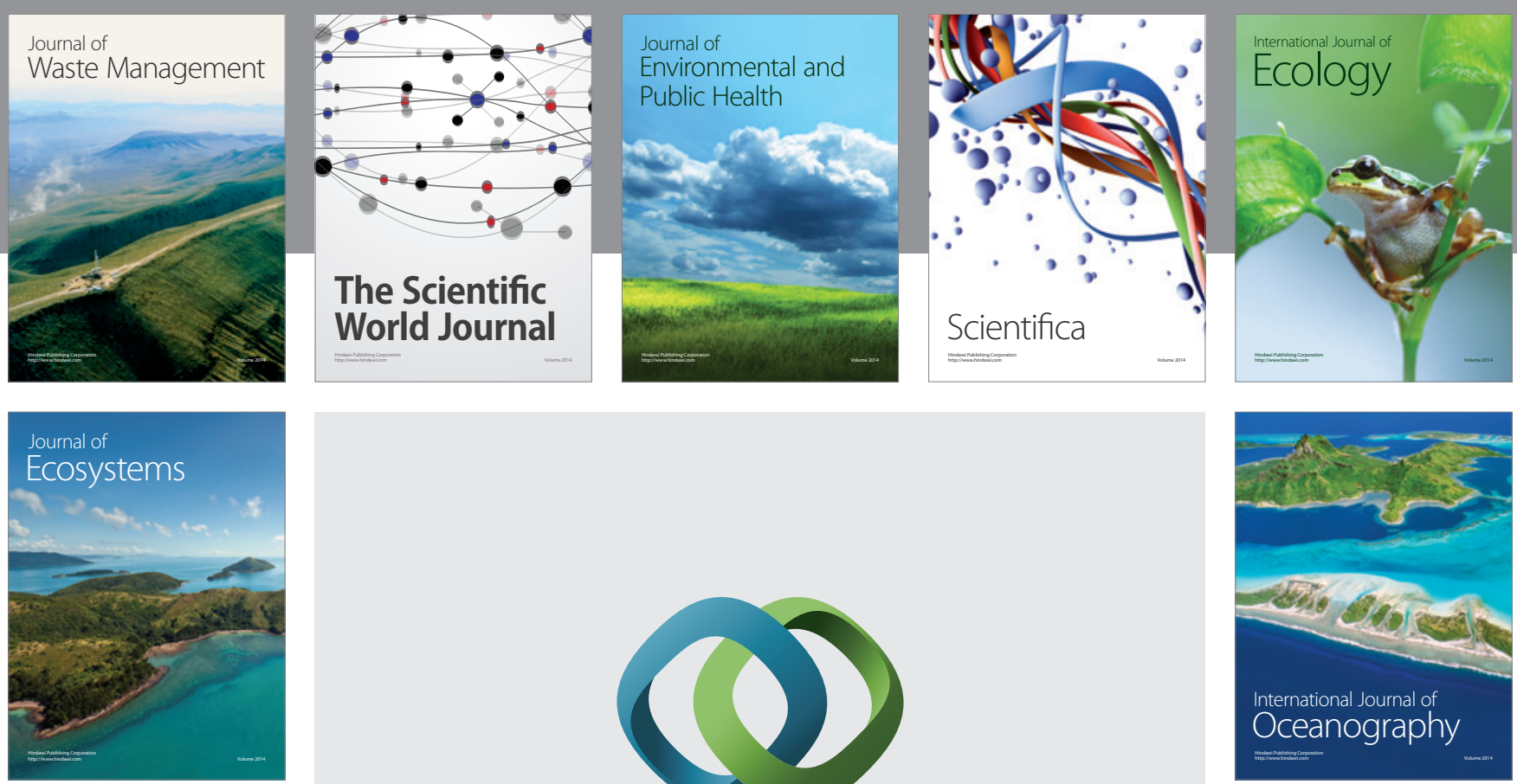

The Scientific World Journal
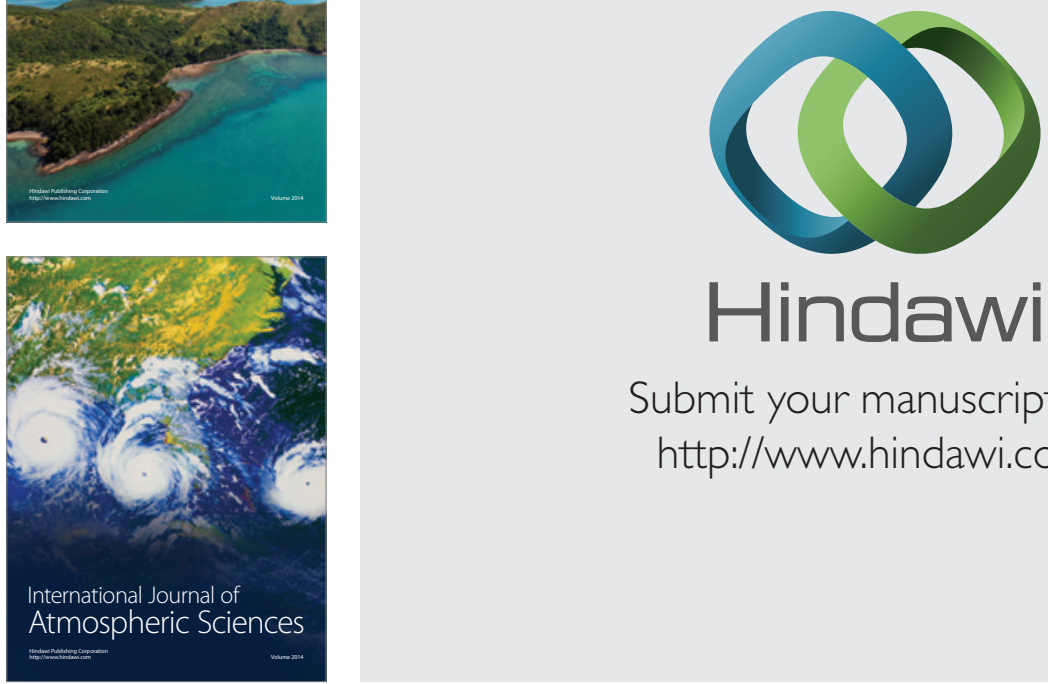

\section{Hindawi}

Submit your manuscripts at

http://www.hindawi.com
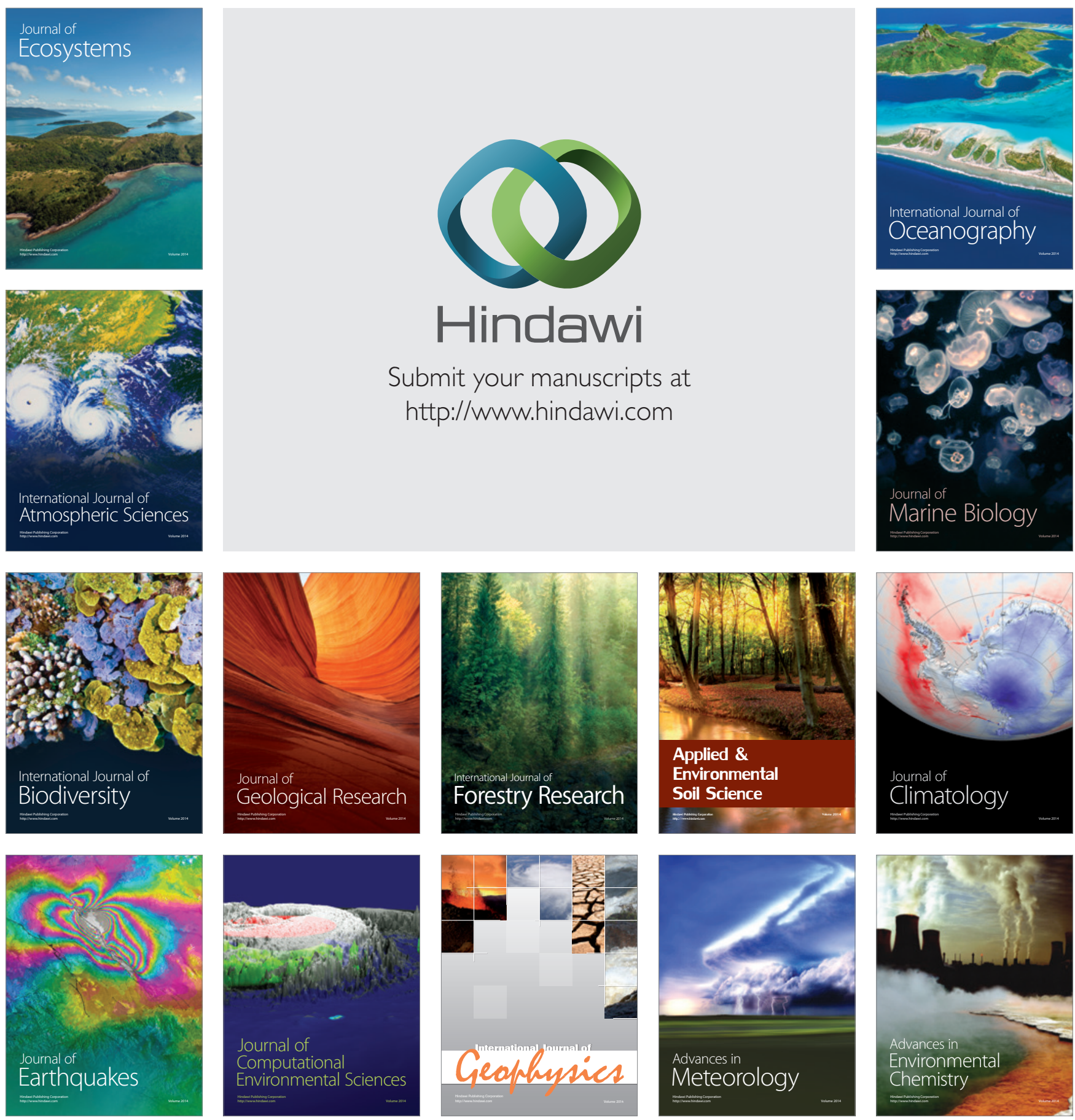